\title{
Parasitological Studies on Trichomonus Vaginalis on Female Patients Presented with Vaginal Discharge at Aswan University Hospital
}

\author{
AHMED K. DYAB, M.D.*; HANY A. FAROUK, M.D.**; MOHAMMED F. MOHAMMED, M.Sc.*** and \\ TASNEEM M. HASSAN, M.D.*
}

The Department of Medical Parasitology, Faculty of Medicine, Asuit University*,

The Department of Gynecology and Obestatric, Faculty of Medicine, Aswan University** and

The Department of Medical Parasitology, Faculty of Medicine, Aswan University***

\begin{abstract}
Background: Trichomonas vaginalis (T.vaginalis) is one of the most common parasitic non viral Sexually Transmitted Infections (STI) in the world. The World Health Organization (WHO) has estimated that 160 million trichomoniasis cases are acquired annually worldwide [1].

Aim of Study: Evaluate different direct laboratory methods used in diagnosis of vaginal trichomoniasis.

Material and Methods: The cross sectional study was carried out on 200 female patients, suffering from vaginal discharge, aged between 20-50 years old. Two vaginal swabs were taken from every patient after taking a concent. All the samples were examined by wet mount, stained by Giemsa, rapid test and Culture on modified Diamond's medium and ELIZA.

Results: This study showed that ELIZA is the gold standered among diagnostic techniques as it detected $\mathrm{T}$. vaginalis in $15 \%$ of suspected patients followed by $13.5 \%$ by culture, then $12.5 \%$ by rapid test and lastly wet mount which detected only $5 \%$ of cases. ELIZA and Culture gave the highest sensitivity, specificity, accuracy, NPV and PPV followed by rapid test. The least sensitive was wet mount. The least specific was Giemsa stain.

Conclusion: The study showed that wet mount method is simple and cheap. Wet mount microscopy is the preferred option for prompt diagnosis of trichomoniasis. It is proved that rapid test is relatively simple to carry out, shows reasonable sensitivity and culture remains the most accurate single method for detecting the presence of $\mathrm{T}$. vaginalis in patient samples. and Diamond's medium is a suitable culture method and is considered as the gold standard of diagnosis of trichomoniasis.
\end{abstract}

Key Words: Trichomonas - Vaginalis rapid test vaginal discharge - ELIZA - Diamond's medium-Aswan.

\section{Introduction}

TRICHOMONAS vaginalis (T.vaginalis) is one of the most common parasitic non viral Sexually

Correspondence to: Dr. Mohammed F. Mohammed, E-mail: mohammedfathy5050@gmail.com
Transmitted Infections (STI) in the world. The World Health Organization (WHO) has estimated that 160 million trichomoniasis cases are acquired annually worldwide [1]. The most risky populations for trichomoniasis are teenage, black races, pregnant women and sexually active females. It is more common in females $(2.7 \%)$ than males $(1.4 \%)$. Studies which were done in Egypt showed a prevalence rate range from $5 \%$ to $9.3 \%$ [2]

Trichomoniasisis a common worldwide sexually transmitted disease caused by the flagellated protozoan Trichomonas vaginalis (T. vaginali). It can be considered as a re-emerging infectious disease. The prevalence of trichomoniasis estimated between 2012 and 2016 by WHO, is 110.4 million cases. Trichomonas vaginalis affects the urogenital tract of male and female especially at childbearing period [3].

The disease stages vary from an asymptomatic carrier state to obvious vaginitis $T$. vaginalis infection is associated with cervicitis, urethritis and serious complications as Pelvic Inflammatory Disease (PID) infertility cervical cancer and HIV transmission. In men, trichomoniasis causes urethritis, complicated with epididymitis, prostatitis and infertility. In addition, T.vaginalis may be associated with cancer prostate. Although, there are different methods for diagnosis of this infection, as staining techniques, immunochromatography and nucleic acid amplification the gold standard method for diagnosis of $\mathrm{T}$. vaginalis is the culture on Diamond's medium [4]

\section{Subjects and Methods}

Study population: This is a cross-sectional study was carried out in the outpatient clinic of Aswan 
University Hospital from March 2018 to March 2019. study to evaluate different laboratory method for diagnosis of T.vaginalis. Two hundred female suffering from vaginal discharge were randomly selected. Inclusion criteria were females of reproductive age group (15-45 years) attending gynecological out-patient clinic complaining of vaginal discharges, pruritus, dysuria, dyspareunia and pain in lower abdomen.

Samples collection: Each patient was subjected to PV examination and non-lubricated sterile speculum examination. After testing the $\mathrm{PH}$ of vagina, four sterilized cotton swabs were collected by using sterile bacteriological swabs from the posterior fornix and end cervixf. Samples were labeled and rapidly transported to the Medical Parasitology Laboratory for processing.

Processing and examination of the samples as follow:

1-Direct wet mount microscopic examination [5]: Within 5 minutes of sample collection, a swab containing the vaginal sample swab was examined for at least 3 minutes using a compound microscope to confirm characteristic morphology and jerky movement of the organism. The preparation must be examined as soon as possible after the collection of specimen.

2- Giemsa staining technique: The saline tube containing the secretion was centrifuged for about 10 minutes at medium speed and stained according and one drop of the vaginal swab-PBS suspension was applied on a microscopic glass slide, air dried, fixed in methanol for 1 minute, stained with $20 \%$ Giemsa for 20 minutes. The slide was rinsed by water to remove excess stain, drainedin a vertical position and left to dry and examined microscopically by X100 to detect trophozoites [6]

3- Modified Diamond's cultural [7]: The third swab was immersed immediately into the culture tube containing $5.0 \mathrm{ml}$ Diamond's medium at $37^{\circ} \mathrm{C}$ incubator for 7 days. The culture was examined microscopically on days $2,4,6$, after inoculation. A positive result was defined as the presence of motile trichomonas at any time. While, a negative result. Culture still revealing no growth i.e. absence of motile trichomonas at all reading.

4- OSOM Trichomonas Rapid test: The test was performed according to manufacturer's instructions [8]. Vaginal swab was placed in a flexible plastic test tube containing $0.5 \mathrm{ml}$ of sample buffer, mixed vigorously, and allowed to stand for lmin. The test dipstick was placed in each tube containing the buffer-sample mixture; the results were read after $10 \mathrm{~min}$. A positive result was indicated by the presence of a blue test line along with end.

5- Enzyme linked immunoassay (ELIZA) [9] Polystyrene microtiter plates were coated with affinity-purified rabbit anti-T. vaginalis antibodies, blocked by incubation with $1 \%$ bovine serum albumin in PBS, and stored at $4{ }^{\circ} \mathrm{C}$ until needed. Assay of the clinical described previously samples was done according to [9] .

\section{Results}

ELIZA is the most sensitive diagnostic techniques as it detected $\mathrm{T}$. vaginalis in $15 \%$ of suspected patients followed by Culture $13.5 \%$ by, then $8 \%$ by Rapid test and lastly wet mount which detected only $6.5 \%$ of cases (Table 1 ).

Table (1): The prevalence of vaginal trichomoniasis among cases using different diagnostic techniques.

\begin{tabular}{lcl}
\hline & \multicolumn{2}{c}{ T. vaginalis positive cases } \\
\cline { 2 - 3 } Procedures & Number (No.) & $\%$ \\
\hline Wet mount & 10 & 5 \\
Giemsa stain & 15 & 7.5 \\
Culture & 27 & 13.5 \\
Rapid test & 25 & 12.5 \\
Eliza & 30 & 15 \\
\hline
\end{tabular}

In comparision between wet mount and rapid test there was statistically significant difference $(p<0.05)$ as the wet mount detected 10 positive cases $(40 \%)$ out of 25 positive cases $(100 \%)$ detected by culture (Table 2 ).

Table (2): Comparison between rapid test of trichomonas vaginalis and wet mount smear for diagnosing T.vaginalis.

\begin{tabular}{|c|c|c|c|c|c|c|c|}
\hline \multirow{3}{*}{$\begin{array}{l}\text { Wet } \\
\text { mount } \\
\text { smear }\end{array}$} & \multicolumn{6}{|c|}{ Rapid test } & \multirow{3}{*}{$\begin{array}{c}p- \\
\text { value }\end{array}$} \\
\hline & \multicolumn{2}{|c|}{ Positive } & \multicolumn{2}{|c|}{ Negative } & \multicolumn{2}{|c|}{ Total } & \\
\hline & No. & $\%$ & No. & $\%$ & No. & $\%$ & \\
\hline Positive & 10 & 40 & 00 & 00 & 10 & 5 & $<0.05$ \\
\hline Negative & 15 & 60 & 175 & 100 & 190 & 95 & $\mathrm{~S}$ \\
\hline Total & 25 & 100 & 175 & 100 & 200 & 100 & \\
\hline
\end{tabular}

In comparision between Giemsa stain and culture there was statistically significant difference $(p<0.05)$ as Giemsa stain detected 15 positive cases $(60 \%)$, out of 25 positive cases $(100 \%)$ detected by rapid test, there is three positive cases detected by rapid test and not by giemsa stain (Table 3 ). 
Table (3): Comparison between rapid test and Giemsa stain for diagnosing $\mathrm{T}$. vaginalis.

\begin{tabular}{lcccccccc} 
& \multicolumn{9}{c}{ Rapid test } \\
$\begin{array}{lccccccc}\text { Giemsa } \\
\text { stain }\end{array}$ & Positive & \multicolumn{2}{c}{ Negative } & \multicolumn{1}{c}{ Total } & $\begin{array}{c}p- \\
\text { value }\end{array}$ \\
& No. & $\%$ & No. & $\%$ & No. & $\%$ & \\
Positive & 15 & 60 & 3 & 1.6 & 18 & 9 & $<0.05$ \\
Negative & 10 & 40 & 172 & 98.2 & 182 & 92 & S \\
Total & 25 & 100 & 175 & 100 & 200 & 100 &
\end{tabular}

In comparison between rapid test and culture there was no statistically significant difference $(p>0.05)$ as rapid test detected 25 positive cases $(92.5 \%)$, out of 27 positive cases $(100 \%)$ detected by culture (Table 4 ).

Table (4): Comparison between culture and rapid test for diagnosing $\mathrm{T}$. vaginalis infection.

\begin{tabular}{|c|c|c|c|c|c|c|c|}
\hline \multirow{3}{*}{$\begin{array}{l}\text { Rapid } \\
\text { test }\end{array}$} & \multicolumn{6}{|c|}{ Culture } & \multirow{3}{*}{$\begin{array}{c}p- \\
\text { value }\end{array}$} \\
\hline & \multicolumn{2}{|c|}{ Positive } & \multicolumn{2}{|c|}{ Negative } & \multicolumn{2}{|c|}{ Total } & \\
\hline & No. & $\%$ & No. & $\%$ & No. & $\%$ & \\
\hline Positive & 25 & 92.5 & 00 & 00 & 25 & 12.5 & $>0.05$ \\
\hline Negative & 2 & 7.5 & 173 & 100 & 175 & 87.5 & NS \\
\hline Total & 27 & 100 & 173 & 100 & 200 & 100 & \\
\hline
\end{tabular}

In comparison between Rapid test and culture there was no statistically significant difference $(p>0.05)$ as rapid test detected 25 positive cases (83.3\%), out of 30 positive cases $(100 \%)$ detected by ELIZA (Table 5).

Table (5): Comparison between culture and ELIZA for diagnosing $\mathrm{T}$. vaginalis infection.

\begin{tabular}{|c|c|c|c|c|c|c|c|}
\hline \multirow{3}{*}{$\begin{array}{l}\text { Rapid } \\
\text { test }\end{array}$} & \multicolumn{6}{|c|}{ ELIZA } & \multirow{3}{*}{$\begin{array}{c}p- \\
\text { value }\end{array}$} \\
\hline & \multicolumn{2}{|c|}{ Positive } & \multicolumn{2}{|c|}{ Negative } & \multicolumn{2}{|c|}{ Total } & \\
\hline & No. & $\%$ & No. & $\%$ & No. & $\%$ & \\
\hline Positive & 25 & 83.3 & 00 & 00 & 25 & 12.5 & $>0.05$ \\
\hline Negative & 5 & 16.7 & 170 & 100 & 175 & 87.5 & NS \\
\hline Total & 30 & 100 & 170 & 100 & 200 & 100 & \\
\hline
\end{tabular}

In comparison between ELIZA and culture there was no statistically significant difference $(p>0.05)$ as culture detected 27 positive cases $(90 \%)$, out of 30 positive cases $(100 \%)$ detected by ELIZA (Table $6)$.
Table (6): Comparison between culture and ELIZA for diagnosing T.vaginalis infection.

\begin{tabular}{|c|c|c|c|c|c|c|c|}
\hline \multirow{3}{*}{ Culture } & \multicolumn{6}{|c|}{ ELIZA } & \multirow{3}{*}{$\begin{array}{c}p- \\
\text { value }\end{array}$} \\
\hline & \multicolumn{2}{|c|}{ Positive } & \multicolumn{2}{|c|}{ Negative } & \multicolumn{2}{|c|}{ Total } & \\
\hline & No. & $\%$ & No. & $\%$ & No. & $\%$ & \\
\hline Positive & 27 & 90 & 00 & 00 & 27 & 13.5 & $>0.05$ \\
\hline Negative & 3 & 10 & 170 & 100 & 173 & 86.5 & NS \\
\hline Total & 30 & 100 & 170 & 100 & 200 & 100 & \\
\hline
\end{tabular}

In comparison between sensitivity, specificity, accuracy and predictive values for different vaginal trichomoniasis diagnostic techniques, ELIZA gives the highest sensitivity, specificity, accuracy, NPV and PPV (100\%)followed by culture (90\%). The least sensitive is wet mount $(40 \%)$ and the least specific is Giemsa stain (60\%) (Table 7).

Table (7): Sensitivity, specificity, accuracy, NPV and PPV of different diagnostic techniques.

\begin{tabular}{lccccc} 
Diagnostic & $\begin{array}{c}\text { Sensitivity } \\
\text { tests }\end{array}$ & $\begin{array}{c}\text { Specificity } \\
(\%)\end{array}$ & $\begin{array}{c}\text { Accuracy } \\
(\%)\end{array}$ & $\begin{array}{l}\text { NPV } \\
(\%)\end{array}$ & $\begin{array}{l}\text { PPV } \\
(\%)\end{array}$ \\
\hline Wet mount & 40 & 100 & 92.5 & 92.1 & 100 \\
Giemsa stain & 60 & 98.8 & 93.5 & 94.05 & 83.33 \\
Rapid test & 83.5 & 100 & 98.5 & 98.2 & 100 \\
Culture & 90 & 100 & 98.5 & 98.2 & 100 \\
ELIZA & 100 & 100 & 100 & 100 & 100 \\
\hline
\end{tabular}

The highest prevalence of vaginal trichomoniasis $(30 \%)$ was recorded in suspected cases having combination of vaginal discharge, itching, dysurea, dysparounia, abdominal and back pain equal (36\% of total positive), while the least prevalence (10\%) was recorded in suspected cases presenting dysuria $(10 \%)$ vaginal discharge only (11.5). Itching only has no value in diagnosis of trichomoniasis. The difference between data in the studied groups was statistically significant $(p$-value $<0.05$ ) (Table 8 ).

Table (8): Frequency of symptoms among studied cases.

Symptom

\begin{tabular}{|c|c|c|c|}
\hline \multirow[t]{2}{*}{$\begin{array}{l}\text { No. of } \\
\text { studied } \\
\text { cases }\end{array}$} & $\begin{array}{c}\text { Positive } \\
\text { cases } \\
\text { of } \mathrm{T} . \\
\text { vaginalis }\end{array}$ & $\begin{array}{c}\text { Negative } \\
\text { cases } \\
\text { of } \mathrm{T} . \\
\text { vaginalis }\end{array}$ & \multirow[t]{2}{*}{$\begin{array}{c}p- \\
\text { value }\end{array}$} \\
\hline & No. $\%$ & No. $\%$ & \\
\hline
\end{tabular}

- Vaginal discharge

$\begin{array}{llllll}40 & 0 & 0 & 40 & 100 & \mathrm{~S}\end{array}$

- Itching

$\begin{array}{lllll}5 & 0 & 0 & 4 & 80\end{array}$

- Infertility

- Vaginal discharge

$\begin{array}{lllll}50 & 5 & 10 & 45 & 90\end{array}$

and itching

- Dysurea and

dysparounia

- Vaginal discharge

$\begin{array}{lllll}20 & 3 & 15 & 18 & 90\end{array}$

dysurea, dysparounia

abdominal pain

\begin{tabular}{llllll}
\hline Total & 200 & 30 & 15 & 170 & 85
\end{tabular}


Purulent yellowish greenish frothy vaginal discharge is the most common character of T.vaginalis discharge ( $28 \%$ of cases) and the least character is watery discharge $(5.7 \%$ of suspected cases). Bloody vaginal discharge has no value in diagnosis. The difference between data in the studied groups was statistically significant ( $p$-value $<0.05)$ (Table 9).

Table (9): Vaginal discharge characters in studied cases.

\begin{tabular}{|c|c|c|c|c|c|c|}
\hline \multirow{2}{*}{$\begin{array}{l}\text { Character } \\
\text { of vaginal } \\
\text { discharge }\end{array}$} & \multirow{2}{*}{$\begin{array}{l}\text { No. of } \\
\text { studied } \\
\text { cases } \\
(n=200)\end{array}$} & \multicolumn{2}{|c|}{$\begin{array}{c}\text { Positive } \\
\text { T. } \\
\text { vaginalis } \\
\text { cases }\end{array}$} & \multicolumn{2}{|c|}{$\begin{array}{c}\text { Negative } \\
\text { T. } \\
\text { vaginalis } \\
\text { cases }\end{array}$} & \multirow[t]{2}{*}{$\begin{array}{c}p- \\
\text { value }\end{array}$} \\
\hline & & No. & $\%$ & No. & $\%$ & \\
\hline - Purulent frothy & 70 & 20 & 28 & 50 & 7.1 & $<0.05$ \\
\hline yellowish green & & & & & & S \\
\hline - Whitish & 40 & 5 & 12.5 & 35 & 8.7 & \\
\hline - Mucoid & 50 & 3 & 6 & 47 & 94 & \\
\hline - Watery & 35 & 2 & 5.7 & 33 & 94 & \\
\hline - Bloody & 5 & 0 & 00 & 5 & 100 & \\
\hline Total & 200 & 30 & 11.1 & 170 & 88.9 & \\
\hline
\end{tabular}

T. vaginalis infection was most prevalent in the age groups $30-35$ years ( $25 \%$ of suspected cases) and it was less prevalent in age ranged from 45 50 years (5\% of suspected cases). The difference between data in the studied groups was statistically significant ( $p$-value $<0.05$ ) (Table 10).

Table (10): The relation between vaginal trichomoniasis and age of studied cases.

\begin{tabular}{|c|c|c|c|c|c|c|}
\hline \multirow[t]{2}{*}{$\begin{array}{l}\text { Age } \\
\text { range }\end{array}$} & \multirow[t]{2}{*}{$\begin{array}{l}\text { No. of } \\
\text { studied } \\
\text { cases }\end{array}$} & \multicolumn{2}{|c|}{$\begin{array}{c}\text { Positive } \\
\text { T. } \\
\text { vaginalis } \\
\text { cases }\end{array}$} & \multicolumn{2}{|c|}{$\begin{array}{l}\text { Negative } \\
\mathrm{T} . \\
\text { vaginalis } \\
\text { cases }\end{array}$} & \multirow[t]{2}{*}{$\begin{array}{c}p- \\
\text { value }\end{array}$} \\
\hline & & No. & $\%$ & No. & $\%$ & \\
\hline $20-25$ & 30 & 4 & 13 & 26 & 86 & $<0.05$ \\
\hline $25-30$ & 50 & 8 & 16 & 42 & 84 & $S$ \\
\hline $30-35$ & 40 & 10 & 25 & 30 & 75 & \\
\hline $35-40$ & 25 & 5 & 20 & 20 & 80 & \\
\hline $40-45$ & 25 & 3 & 12 & 22 & 88 & \\
\hline $45-50$ & 20 & 1 & 5 & 19 & 95 & \\
\hline Total & 200 & 30 & 15 & 170 & 85 & \\
\hline
\end{tabular}

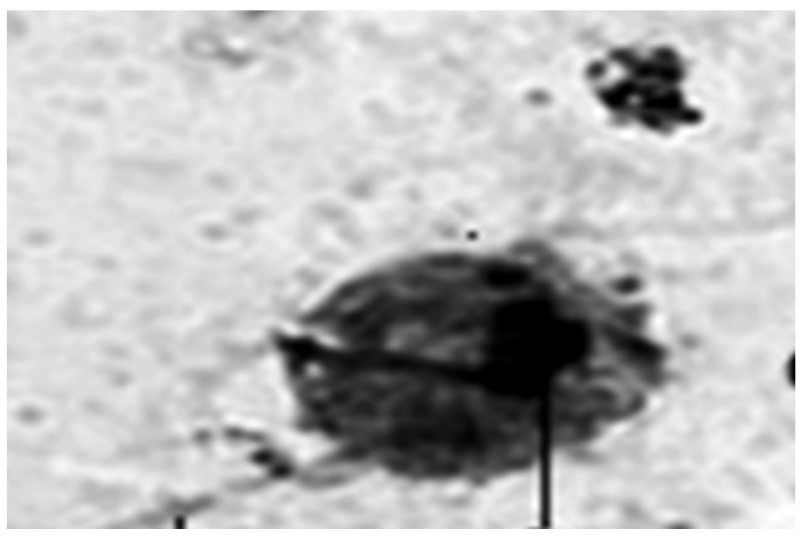

Fig. (1): Gimsa stain of Trophozoite of Trichomonas vaginalis showing flagalle and nuclus.

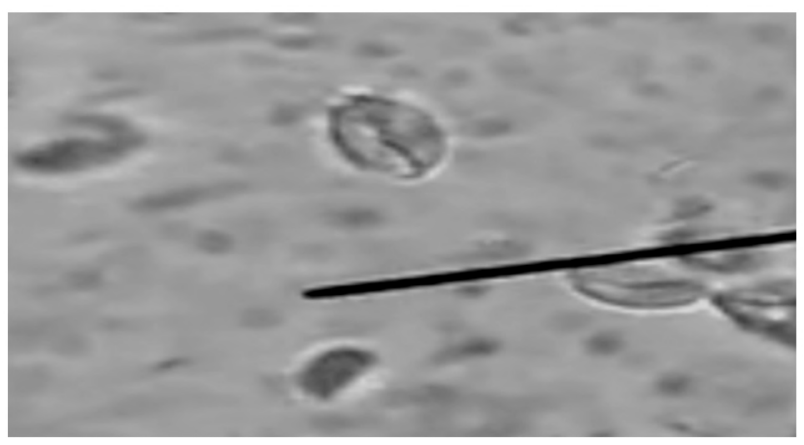

Fig. (2): Wet mount smear of Trophozoite of Trichomonas vaginalis showing flagalle and nuclus (X1000).

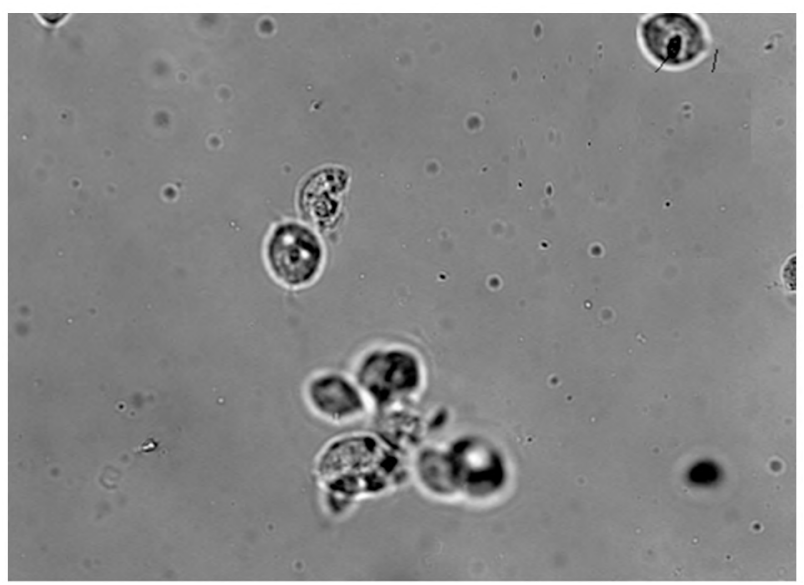

Fig. (3): Culture showing Trichomonas vaginalis Trophozoites with nucleus axostyle and flagella (x640).

\section{Discussion}

Trichomoniasis is the most common nonviral Sexually Transmitted Disease (STD) worldwide, although data are limited for women with a low prevalence of infect). Vaginitis due to Trichomonas vaginalis clinically manifests with symptoms of 
vaginal itching, odor, and discharge. Recent studies also show that $\mathrm{T}$. vaginalis is an important cause of the premature rupture of membranes, premature delivery, pelvic inflammatory disease, urethritis, and chronic prostatitis. Trichomoniasis infection also enhances the transmission of human immunodeficiency virus infection [10].

Microbiology laboratory tests a high volume of vaginal swabs each day for vaginitis pathogens, and $30 \%$ are positive for bacterial vaginosis or candidiasis, although there is a low prevalence of $T$. vaginalis vaginitis based on the detection of motile trichomonads by Wet Preparation examination (WP). Due to the poor sensitivity of Wet mount smear. T. vaginalis cases likely were being missed because of lost flagellate viability during specimen transport [11]. New diagnostic methods for trichomoniasis recently have become commercially available that do not require the presence of viable flagellate, including rapid antigen immunocapillary and nucleic acid amplification tests. It was therefore of interest to compare the performance of the OSOM Trichomonas rapid test (OSOM Trich) (Genzyme Diagnostics, Cambridge, MA) to that of WP for the routine detection of $\mathrm{T}$. vaginalis vaginitis in our laboratory setting [12].

Till today, in developing countries including Egypt, little emphasis has been laid on the importance of decreasing the rates of trichomoniasis even though it has been associated with human immunodeficiency virus acquisition. Because vaginal discharge which is the major symptom of trichomoniasis is a non specific symptom, laboratory diagnosis is must for detecting the infection [13]. Although effective therapeutic agents for treatment of trichomoniasis are widely available, diagnostic difficulties have become the limiting factor in reducing the disease burden. Various laboratory methods have been employed for the detection of trichomoniasis in vaginal discharge which vary in their sensitivity and specificity [13].

Accurate diagnosis of $\mathrm{T}$. vaginalis is affected by many variables, including patient factors, clinician's experience, specimen sampling, processing and test interpretation as well as the skill set and expertise of those doing microscopic assessments. On the other hand, sensitivity, specificity, cost, ease of use and time consuming for the different methods for diagnosing $\mathrm{T}$. vaginalis infection should be also considered [11]

In the present study, wet mount detected 5\% (10 positive cases out of total 200 suspected women). The sensitivity of wet mount was $40 \%$ as it detected 10 positive cases out of total 27 positive cases detected by culture method. The previous results came in coordination with, Nagat et al., [14] who reported that wet mount microscopy detected about half of the culture positive samples 13 (56\%) cases positive by wet mount out of 22 total positive cases and 13 cases positive (56\%) by wet mount out of total 22 positive cases respectively. Schirm et al., [15] who reported $27(67.5 \%)$ cases positive by wet mount out of total 40 positive cases by culture method and Sood et al., [16] who reported that wet mount microscopy detected about half of the culture positive samples $22(55 \%)$ cases positive by wet mount out of 40 total positive cases and 13 cases positive (62\%) by wet mount out of total 21 positive cases respectively. On the other hand, Mahmoud et al., [17] reported 12 cases positive (34.2\%) by wet mount out of 35 total positive cases by culture. Huppert et al., [18] reported that wet mount alone is insufficient for the reliable diagnosis of T. vaginalis infection in women. Gavgani et al., [19] reported 31 cases positive $(33.6 \%)$ by wet mount out of total 92 positive cases by culture.

In many health settings worldwide, wet mount microscopy is the preferred option for prompt diagnosis of trichomoniasis. This method, save time and enables patients to receive treatment in the same day and will reduce clinical over-diagnosis in women presenting with vaginal discharge [20].

Different reports indicated that the sensitivity of wet mount is between $60 \%$ when compared with the culture method [11]

On the other hand, wet mount has its short comings. The sample should be examined as soon as possible, because $\mathrm{T}$. vaginalis is perishable in external conditions. Wet-preparation microscopy is not routinely performed, even in many STI clinic settings and laboratories [21].

Giemsa staining method detected 7.5\% (15 positive cases out of total 200 suspected cases) The sensitivity of Giemsa stained method was $60 \%$ compared to culture method as it detected 15 positive cases, compared to 27 cases positive by culture and 25 positive cases detected by rapid test. In coordination with Nagat et al., [14] who reported that $15(60 \%)$ cases were positive by Giemsa staining method compared to total $27(83.5 \%)$ positive cases by culture. On the Ojuromi et al., [22] who reported that $62(73 \%)$ cases were positive by Giemsa staining method compared to total 85 $(100 \%)$ positive cases by culture. On the other hand Radonjic et al., [5] reported that $11(50 \%)$ of cases were positive by Giemsa stain out of total 
$22(100 \%)$ cases positive by culture method with $50 \%$ sensitivity of Giemsa stain compared to culture method and El Sayed Zaki et al., [23] reported 16 $(48.5 \%)$ positive cases by Giemsa stain compared to total $33(100 \%)$ positive cases by culture.

In the present study, it is observed that wet mount examination, culture and rapid test and ELIZA had $100 \%$ specificity; this could be attributed to the fact that the presence of Trichomonads was determined by its characteristic size, shape and mobility, this what explained by Sood et al., [16]. However, Giemsa staining diagnosed five positive cases which were found to be negative by both wet mount examination and culture. These could be considered false positives as diagnosis by the latter two methods depends not only on size and shape but also on mobility of the parasite.

Rapid test, used for diagnosis of trichomoniasis and is low cost and time consuming [24]. OSOM Trich is an immunochromatographic capillary-flow enzyme immunoassay dipstick test that was performed according to the manufacturer's instructions. Vaginal swabs were tested in batches of 10 , and analysis required 10 to $15 \mathrm{~min}$. A positive result has both a red internal control and a blue positive test line, while the negative result has only a red internal control line. Invalid tests had an absent internal control line. Discrepant results between OSOM Trich and WP were resolved using the Aptima Trichomonas transcription-mediated amplification assay performed according to the manufacturer's instructions (Gen-Probe, San Diego, CA). Specimens were tested in a Gen-Probe DTS 400 instrumentation system using T. vaginalisspecific reagents and Aptima general-purpose reagents (target capture, transcription-mediated amplification, and hybridization protection using primers and probes that specifically target $\mathrm{T}$. vaginalis rRNA). A T. vaginalis patient culture in Diamonds medium was used to inoculate a GenProbe Aptima swab specimen transport tube and an uninoculated Gen-Probe Aptima swab specimen transport tube, which were used as positive and negative controls [11].

In the present study, rapid test detected $12.5 \%$ ( 25 positive cases out of total 200 suspected women). The sensitivity of wet mount was $90 \%$ as it detected 25 positive cases out of total 27 positive cases detected by culture method. The previous results came in coordination with, [25] who confirms that OSOM Trich had improved sensitivity $(90.7 \%)$ compared to that of WP $(60 \%)$ in this context. OSOM Trich also had the excellent specificity required for screening patients with a low preva- lence of infection. Huppert et al. [5,6] recently evaluated OSOM Trich in two separate studies in female populations with a high prevalence of $\mathrm{T}$. vaginalis infection. The initial evaluation used OSOM Trich to rapidly detect $T$. vaginalis in vaginal specimens collected from sexually active women 18 years of age (n 449) presenting with symptoms of vaginitis, exposure to $T$. vaginalis, or multiple sexual partners. Their study population had a high prevalence of $\mathrm{T}$. vaginalis at $23.4 \%$. OSOM Trich detected more T. vaginalis cases, with a sensitivity of $83.3 \%$; that for WP was $71.4 \%$. In a more recent study, sexually active adolescent women aged 14 to 21 years (n 330) were recruited from a teen health center and the emergency department). Vaginal swabs were tested for T. vaginalis using WP, culture (in Pouch T. vaginalis; BioMed Diagnostics), OSOM Trich, and Aptima. Their study group also had a high prevalence of trichomoniasis at $18.5 \%$. The sensitivity of each method was compared to that of a CPS (i.e., any test with positive results). WP had the lowest sensitivity (56\%), while Aptima had the highest sensitivity (98.4\%). Although OSOM Trich (83\%) had lower sensitivity than that of culture $(90 \%)$, test results were available the same day, whereas it takes a several days' delay for culture.

\section{References}

1- HARP D.F., CHOWDHURY and INDRAJIT: Trichomoniasis: Evaluation to execution. Eur. J. Obstet. Gynecol. and Reprod. Biol., 157 (1): 3-9, 2011.

2- ELSHERIF R.H. and YOUSSEF M.A.: Real-time PCR improves detection of $\mathrm{T}$. vaginalis compared to conventional techniques. Comparative Clinical Pathology, 22 (2): 295-300, 2013.

3- MUZNY A., RIVERS C.A., AUSTIN E.L., et al.: T. vaginalis infection among women receiving gynaecological care at an Alabama HIV Clinic. Sex. Transm. Infect., 89: 6 514-8, 2013.

4- KULA T., et al.: Clinical isolates of T. vaginalis concurrently infected by strains of up to four Trichomonas virus species (family Totiviridae) J. Virol., 85: 4258-70, 2011.

5- RADONJIC I.V., DZAMIC A.M., MITROVIC S.M., ARSENIJEVIC A. V.S., POPADIC D.M. and KRANJCIC Z .I.F.: Diagnosis of T. vaginalis infection: The sensitivities and specificities of microscopy, culture and PCR assay. Europian Journal Obstetetrics \& Gynecology Reproductive Biology, 126 (1): 116-20, 2006.

6- GARCIA, et al.: Methods for detection of T. vaginalis in the male partners of infected women: Implications for control of trichomoniasis. J. Clin. Microbiol., 44 (11): 3994-9, 2001.

7- DIAMOND, et al.: Diagnosis of symptomatic and asymptomatic T. vaginalis infection by applying one tube nested PCR to vaginal discharge. J. Egypt. Soc. Parasitol., 29 (3): 1031-46, 1995. 
8- GAYDOS C.A., SCHWEBKE J., DOMBROWSKI J., et al.: Clinical performance of the Solana ${ }^{\circledR}$ Point-of-Care Trichomonas assay from clinician-collected vaginal swabs and urine specimens from symptomatic and asymptomatic women. Expert. Rev. Mol. Diagn., 17: 303-6, 2017.

9- COTCH M.F., PASTOREK J.G., 2 nd , NUGENT R.P., HILLIER S.L., GIBBS R.S., MARTIN D.H., ESCHENBACH D.A., EDELMAN R., CAREY J.C., REGAN J.A., KROHN M.A., KLEBANOFF M.A., RAO A.V. and RHOADS G.G.: Trichomonas vaginalis associated with low birth weight and preterm delivery. Sex Transm. Dis., 24: 353-60, 1997.

10-MORTENSEN, et al.: Methods for detection of T. vaginalis in the male partners of infected women: Implications for control of trichomoniasis. J. Clin. Microbiol., 2006, 44 (11): 3994-9, 2007.

11- HARDICK A., HARDICK J., WOOD B.J. and GAYDOS C.: Comparison between the Gen-Probe transcriptionmediated amplification $T$. vaginalis research assay and real-time PCR for T. vaginalis detection using a Roche Light Cycler instrument with female self-obtained vaginal swab samples and male urine samples. J. Clin. Microbiol., 44: 4197-9, 2006.

12- WENDEL K.A. and K. A. WORKOWSKI: Trichomoniasis: Challenges to appropriate management. Clin. Infect. Dis., 44 (Suppl. 3): S123-S129, 2007.

13- PATIL M.J., NAGAMOTI J.M. and METQUD S.C.: Diagnosis of $T$. vaginalis from vaginal specimens by wet mount microscopy, In Pouch TV culture system and PCR. J. Glob. Infect. Dis., 4 (1): 22-5, 2012.

14- NAGAT A.S., et al.: Direct laboratory methods used in diagnosis of vaginal trichomoniasis Correlation of $\mathrm{T}$. vaginalis to bacterial vaginosis: A laboratory-based study. J. Infect. Dev. Ctries., 4 (3): 156-63, 2015.

15- SCHIRM J., BOS P.A.J., ROOZEBOOM-ROELFSEMA I.K., LUIJT D.S. and MÖLLER L.V.: Trichomonas vaginalis detection using real-time TaqMan PCR. Journal Microbiology Methods, 68 (2): 243-7, 2007.

16- SOOD S., MOHANTY S., KAPIL A., TOLOSA J. and MITTAL S.: In Pouch TV culture for detection of T. vaginalis. Indian J. Med. Res., 125: 567-71, 2007.
17- MAHMOUD M.S., ABDEL-AZIZ S. S., EL-SHERIF E.A. and SWIDAN K.H.: Diagnosis of symptomatic and asymptomatic T. vaginalis infection by applying one tube nested PCR to vaginal discharge. J. Egypt. Soc. Parasitol., 29 (3): 1031-46, 2015.

18- HUPPERT J.S., MORTENSEN J.E., REED J.L., KAHN J.A., RICH K.D., MILLER W.C. and HOBBS M.M. Rapid Antigen Testing Compares Favorably with Transcription-Mediated Amplification Assay for the Detection of T. vaginalis in Young Women. Clin. Infect. Dis., 45 (2): 194-8, 2007

19- GAVGANI A.M., NAMAZ A., GHAZANCHAEI A., ALIZADEH S., SEHHATI F., ROSTAMZADEH S. and AFSANEH DOLATKHAH A.: Prevalence and risk factors of trichomoniasis among women in Tabriz. Iranian J. Clin. Infect. Dis., 3 (2): 67-71, 2008.

20- KASSEM H.H. and MAJOUD O.A.: Trichomoniasis among women with vaginal discharge in Benghazi City, Libya. J. Egypt. Soc. Parasitol., 36 (3): 1007-1006, 2006.

21- SENA A.C., WILLIAM C.M., HOBBS M.M., SCHWEBKE J.R., LEONE P.A., SWYGARD H., ATASHILI J. and COHEN M.S.: Trichomonas vaginalis infection in male sexual partners: Implications for diagnosis, treatment and prevention. Clin. Infect. Dis., 44: 13-22, 2007.

22- SCHWEBKE J.R., LEONE P.A., SWYGARD H., ATASHILI J. and COHEN M.S.: Trichomonas vaginalis infection in male sexual partners: Implications for diagnosis, treatment and prevention. Clin. Infect. Dis., 44: 13-22, 2007.

23- EL-SAYED ZAKI M., RAAFAT D., EL EMSHATY W., AZAB M.S. and HOSSAM H.: Correlation of T. vaginalis to bacterial vaginosis: A laboratory-based study. J. Infect. Dev. Ctries., 4 (3): 156-63, 2010.

24- HOBBS M.M., LAPPLE D.M., LAWING L.F., et al.: Methods for detection of T. vaginalis in the male partners of infected women: Implications for control of trichomoniasis. J. Clin. Microbiol., 44 (11): 3994-9, 2006.

25- CAMPBELL L., WOODS V., LLOYD T., ELSAYED S and CHURCH D.L.: Evaluation of the OSOM Trichomonas rapid test versus wet preparation examination for detection of $\mathrm{T}$. vaginalis vaginitis in specimens from women with a low prevalence of infection. J. Clin. Microbiol., 46 (10): 3467-9, 2008. 


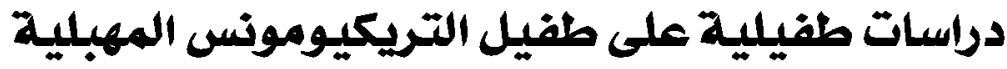

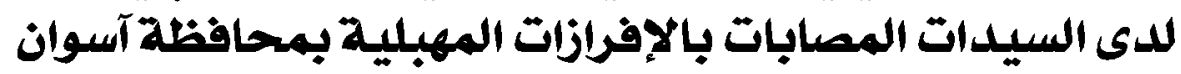

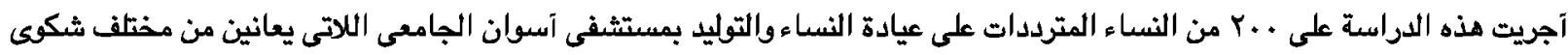

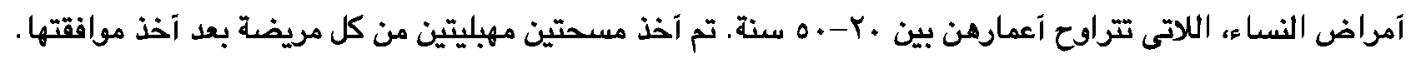

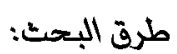

- الفحص المجهرى المباشر لعينة المسحة المهبلية.

- الفحص بإستخدام صبغة (لطذة) الجيمسا.

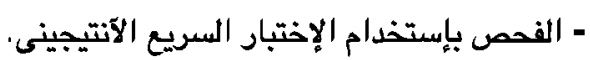

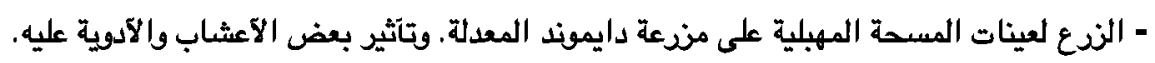
- إلإليزا.

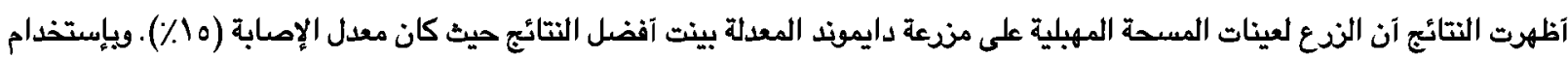

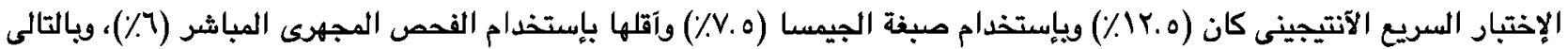

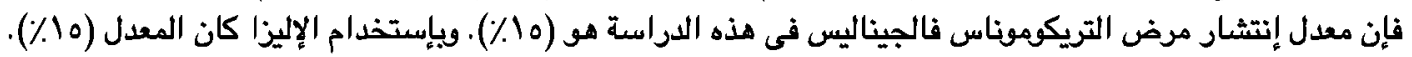

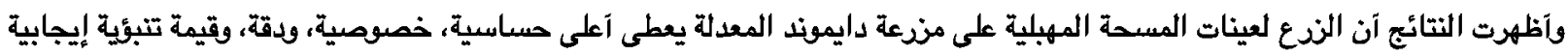
وقيمة تنبوئة سلبية، تليها الإختبار السريع، آما الآقل حساسية هو الفحص المجهرى المباشر بينما الآتل خصوصية والآقل قيمة تنبوئية إيجابية هو صبغة الجيمسا.

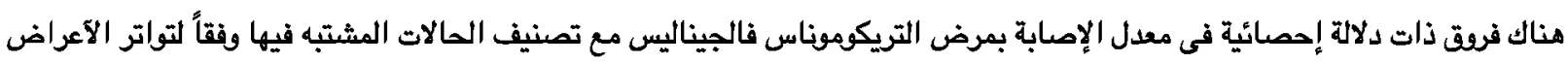

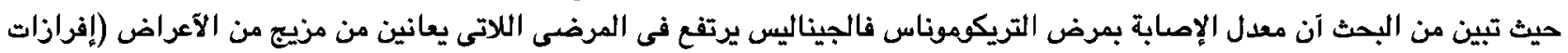

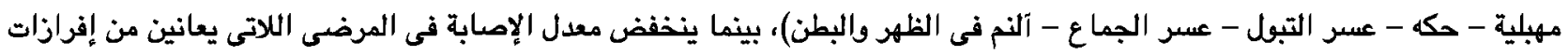
مهبلية فقط. 